Int. J. Dev. Biol. 51: 507-520 (2007)

doi: $10.1387 / \mathrm{ijdb} .072380$ tw

\title{
Axial patterning in the developing vertebrate inner ear
}

\author{
TANYA T. WHITFIELD* and KATHERINE L. HAMMOND \\ Centre for Developmental and Biomedical Genetics, Department of Biomedical Science, University of Sheffield, UK
}

\begin{abstract}
Axial patterning in the vertebrate inner ear has been studied for over eighty years, and recent work has made great progress towards an understanding of the molecular mechanisms responsible for establishing asymmetries about the otic axes. Tissues extrinsic to the ear provide sources of signalling molecules that are active early in development, at or before otic placode stages, while intrinsic factors interpret these signals to establish and maintain axial pattern. Key features of dorsoventral otic patterning in amniote embryos involve Wnt and Fgf signalling from the hindbrain and $\mathrm{Hh}$ signalling from midline tissues (notochord and floorplate). Mutual antagonism between these pathways and their downstream targets within the otic epithelium help to refine and maintain dorsoventral axial patterning in the ear. In the zebrafish ear, the same tissues and signals are implicated, but appear to play a role in anteroposterior, rather than dorsoventral, otic patterning. Despite this paradox, conservation of mechanisms may be higher than is at first apparent.
\end{abstract}

KEY WORDS: axis, inner ear, otic vesicle, otocyst, axial patterning

\section{Introduction: the axes of the inner ear}

The vertebrate inner ear mediates the sense of hearing, and it contributes-together with other sensory and motor systemsto an organism's postural control or balance. To accomplish the latter, the inner ear must be responsive to movement in three dimensions: hence, in most vertebrates, it displays obvious asymmetries about all three body axes-anteroposterior (AP), dorsoventral (DV) and mediolateral (ML) (Fig. 1A, B). In jawed vertebrates, the inner ear comprises three orthogonally arranged semicircular canals (anterior, lateral and posterior), connecting to a medially located crus commune. A series of chambers containing sensory maculae are located ventral to the semicircular canal system, while the endolymphatic duct and sac extend from the dorsomedial part of the ear. In amniotes, a specialised hearing organ, the cochlea, extends ventrally from posterior regions of the ear.

The inner ear arises from a thickening of head ectoderm, the otic placode, which invaginates or cavitates to give rise to an epithelial vesicular structure, the otic vesicle or otocyst. Morphological asymmetries first become evident at these early stages (Fig. 1C, D). In the zebrafish, cavitation begins at the anterior pole of the vesicle before the posterior, and soon afterwards, cell movements result in a thinning of the dorsal otic epithelium and a thickening of ventral epithelium (Haddon, 1997; Riley et al., 1997). In the chick, the DV axis is morphologically obvious at otic cup stages, as the developing endolymphatic duct forms an outpocketing from the dorsal pole of the invaginating otic cup (Brigande et al., 2000a). Molecular studies, however, reveal that asymmetric patterns of gene expression about all three axes appear even earlier, prior to any obvious morphological manifestation of asymmetry. Gene expression patterns in the otic vesicle do not always correlate precisely with the body axes, which are thus somewhat arbitrary points of reference, but as we shall see, the sources of signalling molecules that pattern the ear are often aligned with the body axes. For the purposes of description, therefore, the body axes are useful, and we will use these here.

Although there is a correlation between axial patterning of the otic vesicle and the final structure of the mature labyrinth, it should be remembered that morphogenetic movements, cell migration and differential rates of cell division and cell death distort the relationship between the two. Perhaps the most obvious example is the migration of neuroblasts that give rise to the VIIIth ganglion. In both zebrafish and amniotes, these cells are specified in predominantly anterior regions of the otic placode and vesicle, but give rise to neurons that occupy a predominantly ventral position in the final pattern. Fate mapping and gene expression studies

\footnotetext{
Abbreviations used in this paper: AP, anteroposterior; A, anterior; BMP, bone morphogenetic protein; D, dorsal; DV, dorsoventral; E, embryonic day (mouse stages); FGF, fibroblast growth factor; HH, Hamburger-Hamilton (chickstages); Hh, hedgehog; hpf, hours post fertilization (zebrafish stages); M, medial; ML, mediolateral; L , lateral; P, posterior; r, rhombomere; S, somite (zebrafish stages); V, ventral; Wnt, wingless/int.
} 
have been used to trace other cell and tissue movements that shape the developing ear. In the chick, for example, fate mapping at otic cup stages has shown that there is considerable distortion of different regions of the cup as it invaginates to form a vesicle (Brigande et al., 2000a; Abelló et al., 2007). In the mouse, the relationship between cell position in the otic cup and the final pattern is also complex: Wnt-responsive cells in the dorsomedial region of the otic cup contribute to both dorsal and ventral otic derivatives (Riccomagno et al., 2005). In the zebrafish, there appears to be little change in the relative positions of cells in the otic vesicle between 17 and 48 hours post fertilisation (hpf) (Haddon, 1997), but in the amphibian ear, fate mapping studies indicate that cell mixing is still prevalent at otic vesicle stages, and so the relative positions of cells in the otic vesicle and structures of the mature ear may be harder to interpret (Kil and Collazo, 2001).

Patterns of gene expression have also been used to trace the origin of particular structures in the ear, although this technique is

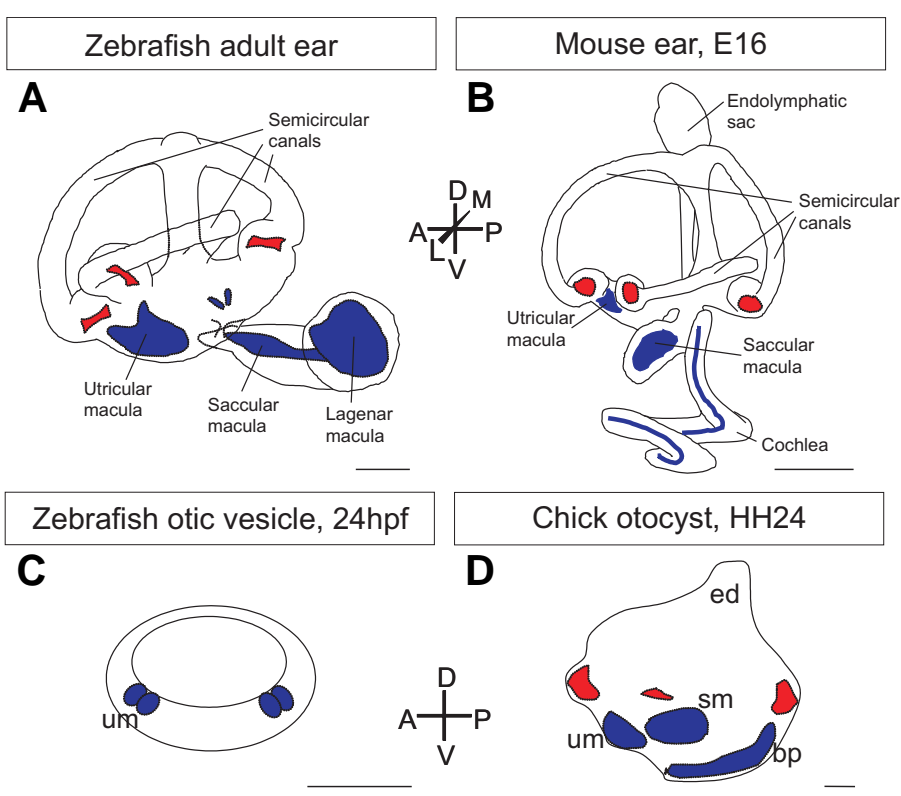

Fig. 1. Axes of the otic vesicle and adult inner ear in zebrafish and amniotes. (A,B) Diagram of a lateral view of the inner ear of an adult zebrafish (A) and E16 mouse (B), showing asymmetries about all three body axes. The positions of the maculae (blue) and cristae (red) are indicated. Scale bars, $500 \mu \mathrm{m}$. (C,D) Schematic diagram of a lateral view of the otic vesicle of a zebrafish at $24 \mathrm{hpf}$ (C) and the chick at HH24 (E4) (D). Scale bars, $100 \mu \mathrm{m}$. There are already obvious morphological asymmetries at these stages: in zebrafish, the dorsal epithelium is thinner than the ventral epithelium; in amniotes, the endolymphatic duct protrudes from the dorsal side. In zebrafish, hair cells (blue) are differentiating in the presumptive utricular and saccular maculae at the anterior and posterior poles, respectively, of the otic vesicle. In the chick, the expression of Bmp4 marks the relative positions of all presumptive sensory areas (the mediolateral dimension is not shown) (adapted from data in Oh et al., 1996). Although the shape of the otic vesicle is distorted during morphogenesis, the relative positions of the sensory patches about the body axes in the mature ear match those at otic vesicle stages. Abbreviations: bp, basilar papilla; ed, endolymphatic duct; sm, saccular macula; um, utricular macula. not as reliable as fate mapping, since changes in expression domains may reflect dynamic changes in gene transcription in addition to cell movements. These data should therefore be treated with caution, but they are sometimes useful in indicating the relative positions of the anlagen of different structures in the ear. For example, in the chick, the fate-mapped proneural region of the otic cup corresponds well to the anterior domain of Fgf10 expression (Abelló et al., 2007), while Bmp expression domains at otic vesicle stages mark the relative positions of all the future sensory patches in the ear (Oh et al., 1996; Wu and Oh, 1996) (Fig. 1D). In the mouse, a dorsomedial domain of Wnt2b expression marks the outpocketing of the vesicle that will give rise to the dorsomedial endolymphatic duct (Ozaki et al., 2004). In the zebrafish, the developing utricular and saccular maculae are marked from early stages in the otic vesicle by the expression of various markers, and the relative positions of these maculae about the AP axis are retained in the adult ear (Fig. 1C).

Thus, asymmetries in the final adult structure of the inner ear are-to a greater or lesser extent, depending on the speciesreflected in early molecular and morphological asymmetries about the axes of the otic vesicle. The purpose of this review is to examine what is known about the mechanisms that establish, interpret and maintain this axial asymmetry in the developing ear.

\section{Equipotentiality about the AP axis of the otic placode and vesicle}

One question concerning the development of any asymmetric organ is whether there is initially a symmetric stage on which pattern is imposed by a later symmetry-breaking event. Although it is not certain whether the otic vesicle is ever truly symmetrical at early stages, the $A$ and $P$ poles of the presumptive otic ectoderm were recognised to be equipotential as early as the 1930s. Rotation of presumptive ear ectoderm in amphibian (salamander) embryos at preplacodal stages (around the time of AP axis fixation) yielded mirror image twinned ears with either double A or double P character (Harrison, 1936; Hall, 1939; Harrison, 1945; Yntema, 1955) (Fig. 2A-C). Similarly, manipulation of the Hedgehog $(\mathrm{Hh})$ signalling pathway in the fish and amphibian embryo can also result in double anterior or double posterior ears (Hammond et al., 2003; Waldman et al., 2007) (Fig. 2D-I; see further discussion in the section on AP patterning below). These enantiomorphic phenotypes demonstrate that the $A$ and $P$ poles of the ear initially have the potential to form either $A$ or $P$ structures; they are reminiscent of other classical developmental axial duplications, such as those of the chick limb following transplantation of the zone of polarising activity, or Drosophila segment polarity phenotypes. Double anterior or posterior ears can also result during regeneration of otic tissue after partial ablation of the placode in Xenopus: these phenotypes are strikingly similar to those generated by the salamander rotation experiments or by manipulations of $\mathrm{Hh}$ signalling in zebrafish (Waldman et al., 2007) (Fig. 2J-O).

The existence of twinned ear phenotypes also suggests that the poles of the otic placode may be specified independently of a mechanism to assign $\mathrm{A}$ or $\mathrm{P}$ identity to either. In the zebrafish, the $A$ and $P$ poles of the otic placode appear to arise by the division of a single symmetrical prosensory domain into two. The proneural gene atoh $1 b$ is initially expressed in a single domain (the sensory 
equivalence group) across the entire $\mathrm{AP}$ axis of the otic placode, but this is later segregated into two domains, one at the anterior and one at the posterior of the placode, which prefigure the appearance of hair cell foci (Millimaki et al., 2007). Refinement of the expression domain is dependent on Notch signalling (Millimaki etal., 2007) and may also require an inhibitory signal from rhombomere 5 ( $r 5)$, preventing hair cell differentiation in the middle of the placode (Lecaudey et al., 2007). The two foci of hair cells that arise at the $A$ and $P$ poles of the ear (the precursors of the utricular and saccular maculae, respectively) initially appear relatively symmetric, and they comprise the same differentiated cell types (hair cells and supporting cells), but the shapes, positions, sizes and polarity patterns of the two maculae will be very different in the mature ear as they develop according to their A or $\mathrm{P}$ position.

\section{Timing of axis formation in the developing ear}

Asymmetric patterns of gene expression arise early in the otic developmental programme, during or even before placode stages. In zebrafish, although otic asymmetry is not morphologically obvious until vesicle stages, asymmetric gene expression is apparent in the otic placode, concomitant with or just after the resolution of the prosensory domain into two separate domains at the $14 \mathrm{hpf}(10$ somite) stage. For example, at $14 \mathrm{hpf}$, delta $A, B$ and $D$-although expressed symmetrically about the AP axis-are expressed on the medial, but not the lateral, side of the placode at the $A$ and $P$ poles (Haddon et al., 1998). By the $16 \mathrm{hpf}$ (14 somite) stage, $h m \times 3$ is expressed strongly at the anterior end of the placode (Adamska et al., 2000). Similarly, in mice, $H m \times 3$ is expressed in the anterior part of the placode, and Wnt6 is detected dorsally, at E8.5 (Hadrys et al., 1998; Lilleväli et al., 2006). For further examples, see Table 1. These data suggest that mechanisms for the specification of axial asymmetry in the ear must be active at or before placode stages.
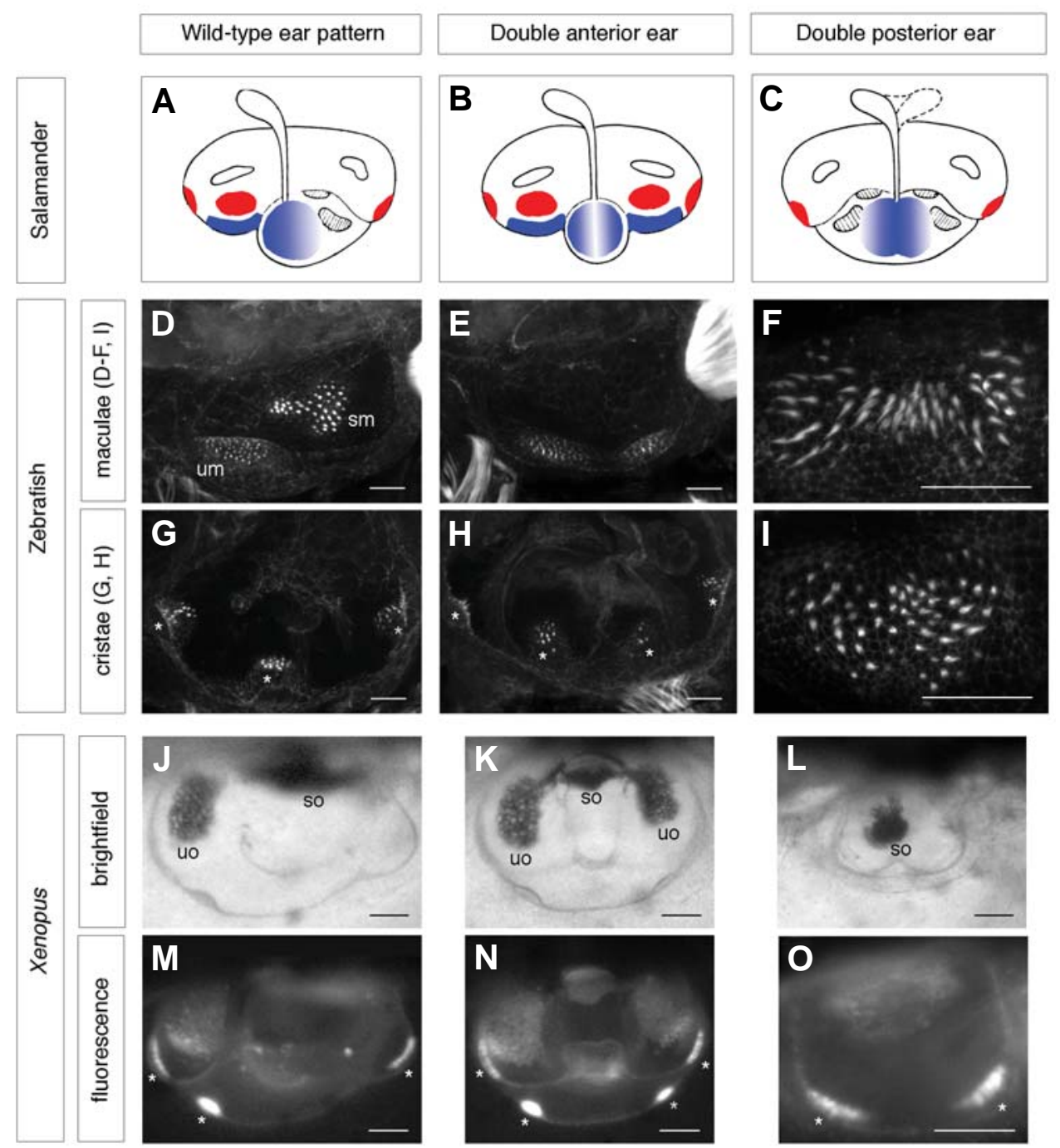

Fig. 2. Examples of axial duplications in the ears of amphibian and zebrafish embryos. (A-C) Diagrams of ear phenotypes obtained by rotations of the otic rudiment about the AP axis in the salamander (reproduced, with permission, from Harrison, 1945). (A) Wild-type ear pattern; (B) double anterior ear; (C) double posterior ear. The utricular and saccular maculae (blue) and cristae (red) are highlighted for clarity. (D-I) Confocal images of ear phenotypes following manipulation of Hh signalling in the zebrafish embryo. Ears are stained with FITC-phalloidin to mark the hair bundles of sensory hair cells in the maculae (D-F, I) or cristae (G, H). (D,G) Wild-type pattern (86 hpf); (E,H) double anterior pattern (86 hpf) obtained by incubation of the embryo from the 10 somite stage to 22 hpf in $50 \mu \mathrm{M}$ cyclopamine to inhibit Hh signalling; (F,I) two examples of a double posterior pattern (mirror-image saccular macula) obtained by injection of shha mRNA into the embryo at the 1-cell stage (72 hpf) (reproduced with permission of the Company of Biologists from Hammond et al., 2003). (J-O) Ear phenotypes at tadpole stage (stage 48) obtained by partial otic placode or otic vesicle ablations in the Xenopus embryo at stages 24-27 (reprinted with permission of Wiley-Liss, Inc., a subsidiary of John Wiley \& Sons, Inc., from Waldman et al., 2007). (J,M) Wild-type pattern; $(\mathbf{K}, \mathbf{N})$ double anterior ear obtained by ablation of the posterior half of the otic placode; $(\mathbf{L}, \mathbf{0})$ double posterior ear obtained by ablation of the anterior half of the otic placode. In all double anterior ears, the utricular macula is duplicated, and four cristae are present. In the double posterior ears, the utricular macula is missing, and the number of cristae is reduced. In all panels, the anterior of the embryo is to the left; (A-I) are lateral views, (J-O) are dorsal views. Abbreviations: sm, saccular macula; so, saccular otolith; um, utricular macula; uo, utricular otolith. Asterisks indicate the position of cristae. Scale bars: (D-I) $25 \mu \mathrm{m}$; (J-O) $100 \mu \mathrm{m}$. 
TABLE 1

\section{GENES EXPRESSED ASYMMETRICALLY ABOUT THE AXES OF THE OTIC PLACODE AND OTIC VESICLE IN ZEBRAFISH, CHICK AND MOUSE}

\begin{tabular}{|c|c|c|c|c|}
\hline Gene & Organism & Expression pattern within the ear & Timing of expression in the ear & References \\
\hline \multicolumn{5}{|l|}{ Anteroposterior } \\
\hline Fgf3 & Mouse & AV & E10 & (Alvarez et al., 2003; Raft et al., 2004) \\
\hline fgf3 & Zebrafish & AV & $22 \mathrm{hpf}$ & (Millimaki et al., 2007) \\
\hline fgf8 & Zebrafish & AV (strong), PV (weak) / AV only & $18 \mathrm{hpf} / 24 \mathrm{hpf}$ & (Léger and Brand, 2002) \\
\hline Fgf10 & Chick & $\mathrm{A}$, later $\mathrm{AV}$ & $\mathrm{HH} 10-19$ & (Alsina et al., 2004) \\
\hline fst & Zebrafish & $\mathrm{P}$ & $24 \mathrm{hpf}+$ & (Mowbray et al., 2001) \\
\hline Lfng & Chick & AV & $\mathrm{HH} 14$ & (Bok et al., 2005) and references within \\
\hline Lfng & Mouse & A & E9.5+ & (Raft et al., 2004) \\
\hline$m f n g$ & Zebrafish & AV & $20 S$ & (Qiu et al., 2004) \\
\hline Otx1 & Mouse & $\mathrm{PV}$ and $\mathrm{L} / \mathrm{VL}$ & E10.25 / E11.5 & (Morsli et al., 1999) \\
\hline otx1 & Zebrafish & VL & $24 \mathrm{hpf}$ & (Kwak et al., 2002) \\
\hline pax 5 & Zebrafish & $\mathrm{A}$ (strong), $\mathrm{P}$ (very weak) & $17 \mathrm{hpf}+$ & (Kwak et al., 2006; Pfeffer et al., 1998) \\
\hline$z p 23$ & Zebrafish & PM & $24 \mathrm{hpf}$ & (Kwak et al., 2002; Kwak et al., 2006) \\
\hline \multicolumn{5}{|c|}{ Anteroposterior and Mediolateral } \\
\hline$H m \times 3$ & Chick & AM initially / later L & $\mathrm{HH} 10+/ \mathrm{HH} 14+$ & (Herbrand et al., 1998) \\
\hline$H m \times 3$ & Mouse & AM initially then becomes $L$ & E8.5 & (Hadrys et al., 1998) \\
\hline hmx3 & Zebrafish & AM initially / later $L$ & $16 \mathrm{hpf}\left(14 \mathrm{~S}_{+}\right) /$late vesicle stages & (Adamska et al., 2000) \\
\hline$H m \times 2$ & Mouse & Same as $H m \times 3$ but later onset & E13.5+ & (Hadrys et al., 1998) \\
\hline GH6 & Chick & $\mathrm{PL} /$ broad L domain & $\mathrm{HH} 9+/ \mathrm{HH} 16$ & (Kiernan et al., 1997) \\
\hline SoHo-1 & Chick & As for $G H 6$ & As for $G H 6$ & (Kiernan et al., 1997) \\
\hline \multicolumn{5}{|l|}{ Mediolateral } \\
\hline Pax2 & Chick & All otic epithelium - stronger M & $\mathrm{HH} 14$ & (Hidalgo-Sanchez et al., 2000) \\
\hline pax2a & Zebrafish & Initially throughout / later M & $3 S / 24 \mathrm{hpf}$ & (Pfeffer et al., 1998; Riley et al., 1999) \\
\hline pax2b & Zebrafish & Initially throughout; later M & $\sim 3 \mathrm{hr}$ later than pax2a & (Pfeffer et al., 1998) \\
\hline$T b \times 1$ & Mouse & $\mathrm{P} / \mathrm{PL} / \mathrm{ADL}$ and $\mathrm{PVM}$ & Placode+ / E9.5 / E10+ & (Raft et al., 2004) \\
\hline$t b \times 1$ & Zebrafish & VL & $24 \mathrm{hpf}$ & (Piotrowski et al., 2003) \\
\hline \multicolumn{5}{|l|}{ Dorsoventral } \\
\hline$D 1 \times 3$ & Chick & Initially entire placode / later DM & $\mathrm{HH} 10 / \mathrm{HH} 12+$ & (Pera and Kessel, 1999) \\
\hline$d l \times 3 b$ & Zebrafish & $\mathrm{D}$ & $24 \mathrm{hpf}$ & (Ellies et al., 1997) \\
\hline$D / x 5$ & Chick & DM & Similar to $D / \times 3$ once otic pit forms & (Pera and Kessel, 1999) \\
\hline$D 1 \times 5$ & Mouse & Initially entire placode / restricts to D & E8.0-8.5 / E10.5+ & (Merlo et al., 2002) and refs within \\
\hline Drapc1 & Mouse & Initially entire placode then DM otic cup & $\mathrm{E} 9.0+$ & (Lilleväli et al., 2006) \\
\hline FgfR2(III)b & Mouse & $\mathrm{D}$ & E9 & (Pirvola et al., 2000) \\
\hline$G b \times 2$ & Chick & Initially entire placode / Restricts to DM & $\mathrm{HH} 10 / \mathrm{HH} 14$ & (Lin et al., 2005) \\
\hline$G b \times 2$ & Mouse & Initially entire placode / Restricts to DM & E8.5 / E9.5 & $\begin{array}{l}\text { (Hidalgo-Sanchez et al,, 2000; } \\
\text { Miyazaki et al., 2006; }\end{array}$ \\
\hline & & & & Sánchez-Calderón et al., 2002) \\
\hline$g b \times 2$ & Zebrafish & DM & $24 \mathrm{hpf}+$ & (Su and Meng, 2002) \\
\hline Otx2 & Chick & VM otic vesicle & HH14+ & $\begin{array}{l}\text { (Hidalgo-Sanchez et al., 2000; } \\
\text { Miyazaki et al., 2006; }\end{array}$ \\
\hline & & & & Sánchez-Calderón et al., 2002) \\
\hline Otx2 & Mouse & $V$ tip of otocyst & E10.25 & (Morsli et al., 1999) \\
\hline Wnt2b & Mouse & D rim / pole of otocyst & E9.5+ & (Lin et al., 2005) and references within \\
\hline Wnt6 & Mouse & D & E8.5+ & (Lilleväli et al., 2006) \\
\hline
\end{tabular}

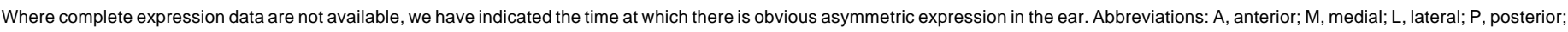
$\mathrm{E}$, embryonic day (mouse); HH, Hamburger-Hamilton stage (chick); hpf, hours post fertilisation (zebrafish); S, somite stage (zebrafish).

Determination or fixation of the otic axes, however, seems to occur some time after signs of otic asymmetry are first apparent. Evidence for this comes from extirpation and grafting experiments performed in the chick (Wu et al., 1998; Bok et al., 2005). In this species, signs of otic AP asymmetry are visible at E1.5 ( $\mathrm{Hh} 10$, placode stage), when, for example, $H m \times 3$ is expressed at the anterior end of the placode. Rotation experiments have indicated that the otic AP axis does not become fixed, however, until around E2.0 (Hh12, otic cup stage). Similarly, the DV axis does not become fixed until after E3.5, although several genes $(G b \times 2, O t \times 2)$ are expressed asymmetrically about the DV axis from as early as E2.5 (Hh14) (see Table 1). The ML axis is fixed for some characters but not others at E2.5.

Sequential fixation of the otic AP axis followed by the DV axis appears to be a general phenomenon, although the exact timing differs for different species. In the salamander, for example, the
AP axis becomes fixed much earlier than in the chick, just as the neural folds are closing and before appearance of the otic placode; the DV axis becomes fixed somewhat later, when the otic vesicle is about to close (Harrison, 1936; Hall, 1939; Harrison, 1945; Yntema, 1955).

\section{Factors required for axis formation: extrinsic and in- trinsic signalling}

The rotation experiments described above suggest that factors both extrinsic and intrinsic to the ear are required for specification and fixation (determination) of the otic axes. At early stages, positioning with respect to surrounding tissues can influence axis formation, while after fixation, rotating the ear cannot override patterning, suggesting that factors intrinsic to the ear act to maintain axial patterning information, and that the ear is either no 
longer responsive to external cues, or that these have ceased. Tissues in the vicinity of the otic ectoderm that may signal to it include the neural tube, notochord, overlying ectoderm, pharyngeal endoderm, migratory neural crest streams and other periotic mesenchyme. Of these, the dorsal neural tube and midline tissues (notochord and floorplate) have been the most extensively studied; the experiments described in the next sections illustrate their importance as sources of extrinsic patterning information. In turn, extrinsic signals are interpreted, maintained and propagated by intrinsic factors expressed within the otic epithelium itself.

Candidates for extrinsic signalling factors from the dorsal neural tube, floorplate and notochord include those of the BMP, Fgf, Hh and Wnt families; note that these are, with the possible exception of $\mathrm{Hh}$ for some species, also expressed within the otic epithelium, where they may act as intrinsic factors to maintain and refine axial patterning. Many factors, both extrinsic and intrinsic to the ear, are involved in specification of more than one axis, and each factor is unlikely to act independently; several studies indicate that there is interaction and cross-talk between different signalling pathways to pattern the ear. In the sections below, we discuss the evidence for the role of these signalling pathways in patterning each of the otic axes. We cover the AP axis separately, but treat the $\mathrm{DV}$ and $\mathrm{ML}$ axes together, since these are rarely affected independently.

\section{Anteroposterior patterning}

\section{Role of the hindbrain in otic AP patterning}

The otic placode develops closely juxtaposed to the hindbrain rhombomeres ( $r$ ), each of which expresses a unique combination of genes at the time of otic axial specification; it is thus an attractive idea that rhombomeres confer AP identity on adjacent otic tissue. In zebrafish, for example, the otic placode initially arises adjacent to $r 4$, but later becomes positioned adjacent to $r 5$, with its anterior and posterior poles (and sites of initial hair cell formation) opposite r4 and r6, respectively (Kimmel et al., 1995; Riley et al., 1997; Ernest et al., 2000). In the chick, the otic vesicle lies adjacent to $r 5$ and $r 6$; here, the $r 5 / 6$ boundary aligns with an otic AP compartment boundary, suggesting that r5- and r6derived factors may confer $\mathrm{A}$ and $\mathrm{P}$ identity, respectively, on the otic vesicle (Brigande et al., 2000b) (see Fig. 5).

Fig. 3. Examples of mutant phenotypes affecting axial patterning at the otic vesicle stage. (A,B) Disruption of the otic AP axis in the zebrafish val/mafb mutant (dorsal views). Expression of anterior markers ( $\mathrm{hm \times 3}$, pax5, fgf8; purple) extends posteriorly around the medial wall of the otic vesicle, while expression of a posterior marker (zp23; light blue) is lost (adapted from data in Kwak et al., 2002). The photographs show the expression of $\mathrm{hm} \times 3$ at $25 \mathrm{hpf}$; arrowheads mark the posterior boundary of expression. (C,D) Disruption of the otic ML axis in the mouse Raldh2-- mutant (dorsal views). Expression of a medial marker ( Pax2; light blue) is lost, while expression of a lateral marker ( $\mathrm{Hm} \times 3$; purple) is expanded throughout the otic epithelium ladapted from data in Niederreither et al., 2000). (E,F) Disruption of the otic DV axis in the mouse $\mathrm{Shh}^{-1}$ mutant (transverse sections). Expression of the dorsal marker Dlx5 (purple) extends ventrally, while expression of the ventral marker Otx2 (light blue) is lost (adapted from data in Riccomagno et al., 2002). All drawings are schematic diagrams, not to scale; they show only a subset of the genes affected in each case.
Evidence from the zebrafish supports a role for rhombomeres in otic AP patterning: specifically, it has been proposed that $\mathrm{r} 4$ is the source of a signal that acts to anteriorise the ear. In homozygous valentino (val/mafb) mutant embryos, rhombomere boundaries are lost posterior to $r 3 / 4$, and $r 5$ and $r 6$ territories are replaced by an undivided rhombomere, $r X$, with some of the characteristics of $\mathrm{r} 4$; concomitantly, expression domains of anterior otic markers (pax5, $h m \times 3$ ) extend posteriorly, adjacent to rX, while expression of the posterior marker $z p 23$ is lost in the ear (Kwak et al., 2002) (Fig. 3A, B). A similar anteriorisation of the ear is seen in homozygous tcf2 (vhnf1) zebrafish mutants, which also have disrupted rhombomere patterning and lack expression of val/mafb in the hindbrain (Hernandez et al., 2004; Lecaudey et al., 2007). In tcf2 mutant embryos, expression domains of anterior otic markers ( $f g f 8$, pax $5, h m \times 3$ ) extend posteriorly or are duplicated at the posterior of the otic vesicle, while expression of fst (follistatin), a posterior otic marker, is often absent (Lecaudey et al., 2007). Note that the tcf2 and val/mafb mutant phenotypes, although similar, are not identical: duplications (rather than ex-

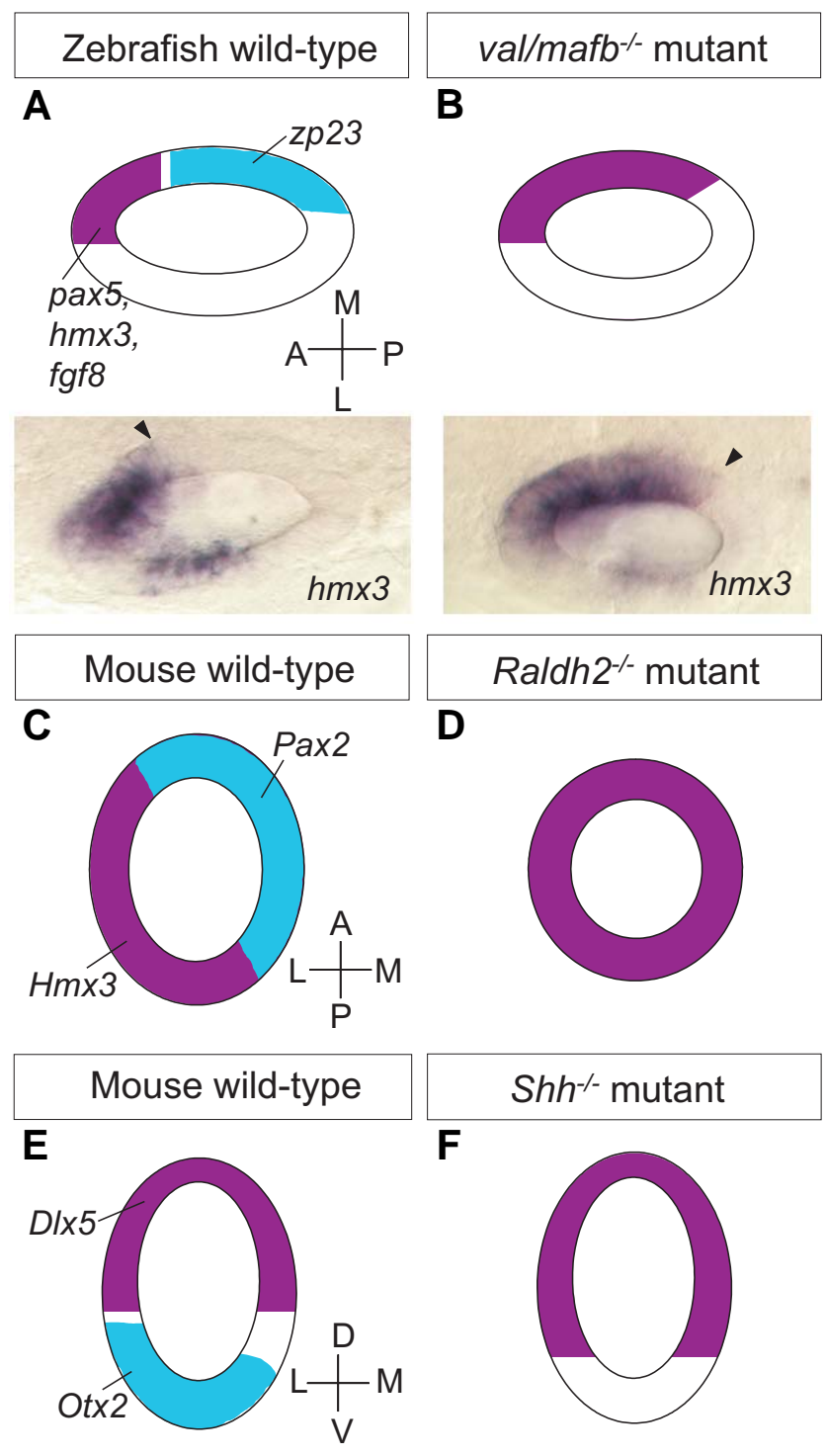


pansions) of anterior markers were not described in val/mafb mutants, and there are also some differences in DV defects in the ear between the two mutants. While it is likely that some effects of the tcf2 mutation are mediated through the loss of val/mafb expression, some aspects appear to be independent.

Both val/mafb and tcf2 (vhnf1) code for transcription factors expressed in $r 5$ and $r 6$ of the hindbrain, and therefore their influence on the ear is likely to be indirect, via the transcriptional regulation of one or more diffusible factors. In val/mafb mutants, effects may be mediated in part by the expansion of $f g f 3$ expression in the hindbrain: normally limited to $r 4$, this now extends posteriorly from the $\mathrm{r} 3 / 4$ boundary adjacent to the entire length of the otic placode. Accordingly, depletion of Fgf3 signalling using an antisense morpholino suppresses the val/mafb ear phenotype, reducing expression of pax 5 and $h m \times 3$ and resulting in the expansion of zp23 expression into anterior regions of the ear (Kwak et al., 2002). In the tcf2 mutant, posterior expansion of fgf3 expression in the hindbrain is even more dramatic than in val/ mafb mutants (Hernandez et al., 2004) and thus a similar mechanism may apply.

Although these results are suggestive that r4-derived Fgf3 is sufficient for the acquisition of anterior identity in the zebrafish ear, there is a caveat: $f g f 3$ is also expressed at the anterior of the otic vesicle (Walshe and Mason, 2003), and knockdown of earderived Fgf3 may contribute to the morpholino-mediated suppression of defects in the val/mafb mutant. In addition, other factors may be involved: the expression patterns of wnt 1 and $w n t 3 a$ in the dorsal hindbrain are also disrupted in tcf2 mutants (Lecaudey et al., 2007), and wnt1 expression is variably abnormal in posterior rhombomeres in val/mafb mutants (Riley et al., 2004). Although not yet tested directly, it is possible that a reduction in wnt expression contributes to the otic phenotype in both mutants; note that hindbrain-derived Wnts are known to be required for otic DV patterning in the mouse (see below).

It will be of interest to examine otic AP patterning in other zebrafish mutant backgrounds that disrupt genes required for the establishment of val/mafb or tcf2 expression, such as the spg/ pou2 mutant (Burgess et al., 2002; Hauptmann et al., 2002) or following treatment to disrupt the RA signalling pathway (Hernandez et al., 2004; Maves and Kimmel, 2005). Mutations in a number of other genes also disrupt rhombomeres or rhombomere boundaries in the posterior hindbrain of the zebrafish, including members of the Hox, Irx, Meis and Pbx families (Moens and Prince, 2002; Lecaudey et al., 2004), and it is likely that these too will have concomitant effects on otic patterning.

In amniotes, a role for rhombomeres in otic AP patterning is less clear. Although rotation of the otic placode in the chick embryo suggests that extrinsic factors influence AP specification, rotation of the hindbrain itself suggests that this tissue is less important in this species than in zebrafish: reversal of the AP axis of r4-7 of the chick hindbrain at E1.5 did not affect otic AP patterning (Bok et al., 2005). Nevertheless, this does not rule out a role for the hindbrain in otic AP patterning prior to E1.5; some Hmx family genes, for example, are already expressed in AP restricted otic domains at this time (see Table 1). There also appear to be differences in the mechanism of hindbrain signalling to the ear between the zebrafish and the mouse. Several mouse mutants have been examined in which hindbrain rhombomere pattern is disturbed but AP patterning in the otic vesicle appears relatively normal, including the Egr2 (Krox20)\% mutant and the $R A R a^{-/} ; R A R b^{-/}$double mutant (see discussion in Brigande etal., 2000a). Also, while the transcriptional relationship between Tcf2 I $v H N F 1$ and kr/Mafb (the murine orthologues of tcf2 and val/ mafb, respectively) in $\mathrm{r} 5$ and $\mathrm{r} 6$ of the hindbrain is conserved (Kim etal., 2005), mutations in kr/Mafb result in a reduction, rather than the expansion seen in zebrafish, of Fgf3 expression in the hindbrain. Consistent with this, mouse $\mathrm{Fgf3}^{-1-}$ mutants display similar ear defects to those in kr/Mafb mutants (Mansour et al., 1993; McKay etal., 1996). Unlike the val/mafb phenotype, the ear defects in $\mathrm{kr} / \mathrm{Mafb}$ and $\mathrm{Fgf3}^{-/-}$mutants primarily affect the DV axis, rather than the AP axis of the ear; these are discussed in the DV section below.

\section{Role of the midline in otic AP patterning}

It is conceptually straightforward to understand how localised sources of inductive factors from specific hindbrain rhombomeres might influence otic AP pattern. It is less obvious why midline tissues (notochord and floorplate), which have no overt AP patterning in the region of the ear themselves and are apparently equidistant from the entire otic AP axis, should have differential

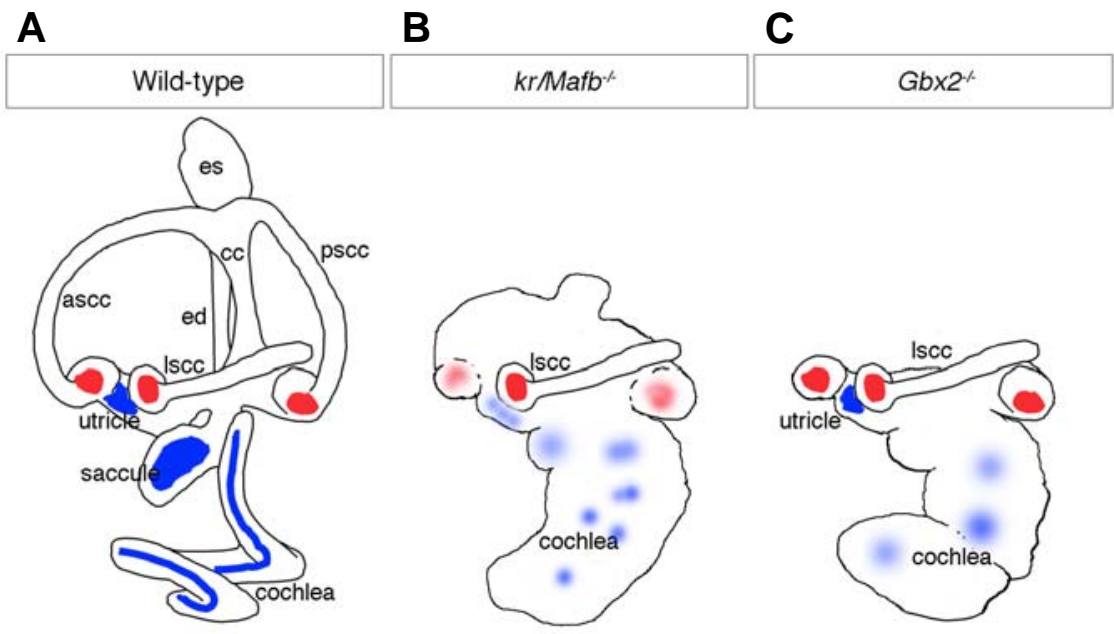

Fig. 4. Similarity of axial patterning defects between $\mathrm{kr}^{\mathrm{Mafb}} \mathrm{Ma}^{-/}$and $\mathrm{Gb}^{-/-}$mutant phenotypes in the mouse. (A) Wild-type mouse inner ear at E16. (B,C) Ear phenotypes in $\mathrm{kr} / \mathrm{Mafb}^{-1-}$ mutants (E15.5, Type II) (B) and Gbx2- mutants (E15.5, Type III) (C). Both mutants show a similar wide spectrum of defects; examples of relatively strong phenotypes are shown for each. The anterior and posterior semicircular canals, crus commune and endolymphatic duct are missing, and the cochlea is grossly distended ladapted from data in Lin et al., 2005 and Choo et al., 2006). Blue shading indicates maculae; red indicates cristae. Light shading indicates poorly differentiated sensory organs. The similarity of the two phenotypes, together with expression data ( $\mathrm{Gb} \times 2$ expression is lost in the ears of $\mathrm{kr} / \mathrm{Mafb}^{-1-}$ mutants), strongly suggest that Gbx2 acts downstream of a kr/Mafb-dependent hindbrain signal. Abbreviations: ascc, Iscc, pscc, anterior, lateral (horizontal) and posterior semicircular canals; cc, crus commune; ed, es, endolymphatic duct and sac. 
effects on the $A$ and $P$ poles of the otic vesicle. Nevertheless, data from our lab suggest that Hedgehog $(\mathrm{Hh})$ signalling from the notochord and floorplate plays a role in the development of posterior otic structures in the zebrafish (Hammond et al., 2003). Hh genes are strongly expressed in both the floorplate and notochord of the zebrafish embryo, while genes whose products are required for transduction of the Hh signal (ptc, smo and $g / I$ ), are expressed in the otic epithelium. Moreover, ptc1 - a target of $\mathrm{Hh}$ signalling - is expressed in a $\mathrm{Hh}$ dependent manner in the ear, suggesting that the effect of $\mathrm{Hh}$ on the ear is direct. When Hh signalling is absent or severely reduced, posterior otic structures fail to form and the ear displays a mirror image duplication of anterior regions, similar to the enantiomorphic ears observed by Harrison (Fig. 2). A recent study has reported a very similar finding in Xenopus: here, injection of mRNA coding for the $\mathrm{Hh}$ inhibitor Hip results in mirror image duplications of anterior inner ear structures (Waldman et al., 2007). When the Hh pathway is activated ectopically in the zebrafish, by injection of shh or dominant negative PKA RNA, we see the reverse phenotype: ears lose anterior otic structures and show a mirror image duplication of posterior regions (Hammond et al., 2003) (Fig. 2).

Taken together, these data demonstrate that $\mathrm{Hh}$ signalling is both necessary and sufficient for the acquisition of posterior otic identity in zebrafish and in Xenopus. In zebrafish, the closest source of $\mathrm{Hh}$ for patterning the ear appears to be the midline, and the two orthologues of mammalian Shh, shha and shhb (previously twhh), are involved (Hammond et al., 2003). In Xenopus, the source of Hh signalling has not been confirmed, but the Bhh gene is expressed in the ear itself (Ekker et al., 1995). In the mouse ear, any AP effects from the disruption of $\mathrm{Hh}$ signalling, if present, are much less obvious than in the fish. Instead, a loss of Hh signalling primarily affects DV patterning (discussed below).

Note that although there are some similarities, the disruption of AP patterning when $\mathrm{Hh}$ signalling is absent in the zebrafish is quite distinct from that seen in tcf2 or val/mafb mutants: despite the duplication of sensory patches at later stages, we do not see duplication or expansion of the anterior markers fgf8 and pax 5 in the early otic vesicle. This could indicate that the maintenance, rather than the initiation, of AP patterning is disrupted when $\mathrm{Hh}$ signalling is lost. There are also other differences: the ears of $\mathrm{Hh}$ pathway mutants often have an additional, ectopic crista (Hammond et al., 2003), whereas in tcf2 mutants, cristae are reduced (Lecaudey et al., 2007). In addition, several markers of DV pattern remain unaffected when $\mathrm{Hh}$ signalling is absent in the zebrafish, whereas the tcf2 mutation disrupts both the AP and DV otic axes (Lecaudey et al., 2007).

A role for $\mathrm{Hh}$ signalling from the midline in otic AP patterning presents a paradox: how can a linear source of $\mathrm{Hh}$ affect the $\mathrm{A}$ and $P$ poles of the vesicle differently? The position of the otic vesicle could provide an explanation: although the otic placode is aligned parallel to the midline, by $24 \mathrm{hpf}$, the posterior pole of the otic vesicle is closer to the midline source of $\mathrm{Hh}$ than the anterior (our unpublished data). Concomitantly, ptc1 becomes restricted to posterior otic regions (Hammond et al., 2003). It is not clear, however, whether this corresponds to the time at which $\mathrm{Hh}$ is required for otic patterning. Alternative explanations (yet to be tested) include the possibility that cells specified by Hh signalling migrate to posterior regions of the otic vesicle as the ear develops. It is also possible that $\mathrm{Hh}$ antagonises or synergises with other more localised AP determination factors, such as Fgf3 from r4, to maintain otic AP pattern. For a summary of otic AP patterning in the zebrafish, see Fig. 6A.

\section{Intrinsic factors for interpretation of AP patterning informa- tion}

As described in the previous sections, changes in extrinsic signalling disrupt patterning in the otic vesicle, as measured by changes both to morphological pattern and to gene expression patterns within the otic epithelium. If these latter genes are not merely markers of position in the otic vesicle, but play an active role in interpreting extrinsic signals, we would expect their loss to have similar effects on AP patterning in the ear. Where mutation or knockdown of an intrinsic otic gene results in a phenocopy of all or a subset of the defects seen for disruption of an extrinsic factor, we can conclude that this gene is likely to be involved in the reception or interpretation of that signal.

At present, there are rather few examples where the loss of function of genes intrinsic to otic epithelium yield AP patterning defects, and none are known that precisely phenocopy the defects seen in the zebrafish hindbrain or midline mutants. In the zebrafish, for example, a reduction in the expression or function of pax5 (an anterior marker, expanded in the anteriorised ears of val/mafb and tcf2 mutants) results in the loss of some anterior (utricular) hair cells, but no disruption of overall AP patterning (Kwak et al., 2006). This suggests that Pax5 plays a role in 
A

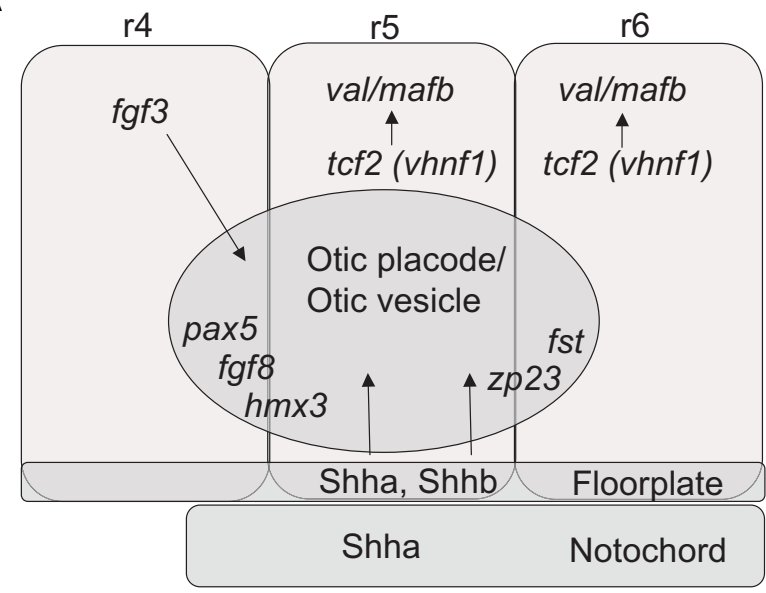

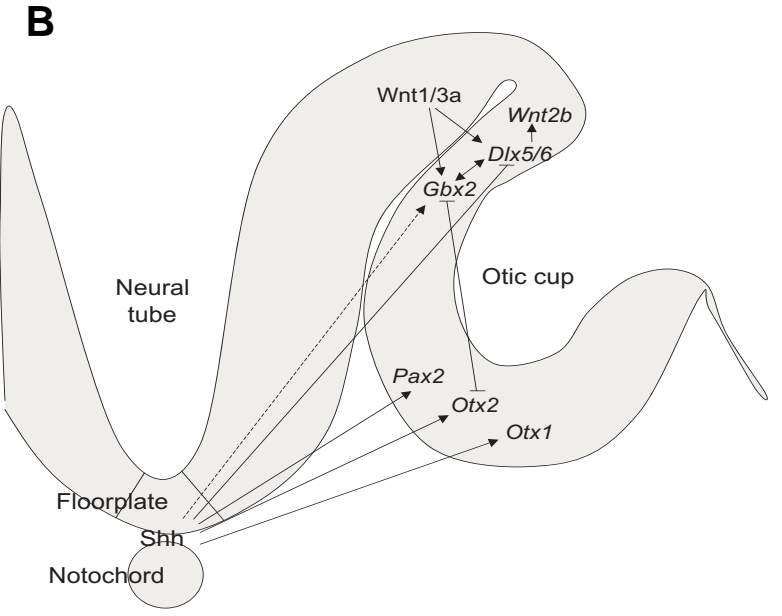

Fig. 6. Summary diagrams of axial patterning in the otic placode, cup and vesicle. (A) Schematic diagram of patterning influences for the zebrafish otic AP axis (not to scale). Fgf3 from r4 and Shh from the midline provide anterior and posterior signals, respectively. Contribution from Wnt genes is likely (see text and Fig. 5). Expression of fgf3 is excluded from $r 5$ and $r 6$ by the activity of tcf2/vhnf 1 and val/mafb. A selection of genes expressed at the anterior ( $\mathrm{hm \times 3}, \mathrm{pax5}, \mathrm{fgf8}$ ) and posterior ( $\mathrm{fst}, \mathrm{zp} 23$ ) of the otic vesicle is indicated. (B) Schematic diagram of patterning influences for the DV and ML axes of an amniote otic cup (a combination of chick and mouse data). Shh from the midline and Wnts from the dorsal hindbrain provide ventral and dorsal signals, respectively. A selection of genes expressed in ventral ( Otx1, Otx2), medial ( Pax2) and dorsal ( Gbx2, Dlx5/6, Wnt2b) regions of the otic cup and vesicle is indicated. Arrows do not necessarily imply a direct interaction. The dotted line indicates a role in maintenance, rather than establishment, of expression. Adapted from data in references cited in the text.

anterior development in the ear, and specifically in the production or survival of hair cells in the anterior macula.

In the mouse, $\mathrm{Tbx} 1$ has been proposed as a determinant for AP patterning within the otic vesicle (Raft et al., 2004), but it is not clear which extrinsic signals regulate its expression in the otic epithelium; expression here is not dependent on Hh signalling, for example (Riccomagno et al., 2002). In Tbx $11^{-1-}$ mouse embryos, expression of some anterior otic markers (Ngn1, NeuroD, Lfng, Fgf3 ) extends posteriorly, expression of Otx1 (a posteroventrolateral marker) is lost, and the rudiment of the VIIIth ganglion, which normally occupies an anteromedial position beneath the otic vesicle, is duplicated at the posterior (Raft et al., 2004; Arnold et al., 2006). An alternative interpretation, however, is provided by Xu et al. (2007), who claim that axial patterning defects are due to a loss of tissue rather than a true anteriorisation of the otocyst. Although it is expressed in both the otic epithelium and surrounding tissues, Tbx 1 certainly qualifies as an intrinsic factor for otic patterning: the requirement for Tbx 1 function in the otic epithelium has been elegantly demonstrated using tissuespecific conditional knockout approaches (Arnold et al., 2006; Xu et al., 2007).

\section{An AP organiser for the otic vesicle?}

The existence of phenotypes involving duplication of the otic $\mathrm{AP}$ axis and the presence of localised sources of diffusible signalling molecules-both in the vicinity of the ear and within the otic epithelium-is reminiscent of other organ systems patterned by an organiser, and it has been proposed that an organiser may also exist to pattern the AP axis of the ear (Léger and Brand, 2002). Although an organiser for the otic AP axis has not been definitively identified, this is a credible idea. Classically, an organiser is defined operationally; it is often the source of a morphogen that establishes pattern in a concentration-depen- dent manner. For the ear, this source of patterning information may either be outside the otic region (such as $\mathrm{r} 4$, or rhombomere boundaries) or may be within the otic epithelium itself, such as the expression domains of $f g f 3$ and $f g f 8$ at the anterior, or fst at the posterior, of the zebrafish otic vesicle. Hh clearly acts as a morphogen in other systems in which there are mirror image phenotypes (see discussion in Hammond et al., 2003), but for the ear, since there is no obvious localised source of $\mathrm{Hh}$ or clearly localised response to its activity, it is not clear whether $\mathrm{Hh}$ is acting in an organising capacity, or is perhaps required for the establishment or maintenance of such an organiser. Further experiments involving targeted cell ablations, or the conditional misexpression or knockdown of genes in specific areas of otic epithelium, will be required to identify any tissue in the ear that may have organising properties and to determine which of the signals are instructive and which permissive for the establishment of otic AP patterning.

\section{Dorsoventral and mediolateral patterning}

\section{Role of the hindbrain in DV/ML patterning}

Rhombomeres in the hindbrain display distinct differences in gene expression along the DV axis and so, in addition to their role in otic AP patterning, may also provide cues to direct DV pattern in the adjacent otic placode or vesicle. Harrison provided early evidence that the hindbrain is required for the acquisition of dorsal otic identity. Specifically, grafting a second hindbrain ventral to the otic placode in amphibian embryos induced the formation of a second endolymphatic duct (ED)—normally a dorsomedial structure-from the ventral part of the ear (Harrison, 1945). In the chick, ablation or DV rotation of $r 4-r 7$ of the neural tube indicates that signals from the dorsal neural tube are both necessary and sufficient for the acquisition of dorsal otic fates in this species (Bok et al., 2005). 
Mutant phenotypes in the mouse also demonstrate the importance of signalling from the hindbrain for both $\mathrm{DV}$ and $\mathrm{ML}$ patterning in the ear. In mice homozygous for mutations in $\mathrm{kr} / \mathrm{Mafb}$ (the orthologue of zebrafish val/mafb), specification of r5 and r6 of the hindbrain fails and dorsal otic structures do not form (Deol, 1964). Detailed analysis of kr/Mafb embryos reveals small, cystic, poorly differentiated ears: the ED does not form, the anterior and posterior semicircular canals and cristae are often absent and the cochlea is distended (Deol, 1964; Choo et al., 2006) (Fig. 4). Expression of the dorsal markers Gbx2, D/x5 and $W n t 2 b$ is lost from the otic vesicle, while expression of the ventral marker Otx2 is expanded, which may account for the cochlear defects (Choo et al., 2006). The hindbrain is therefore required not only for the induction of dorsal otic identity, but also for the repression of ventral otic identity. Similar hindbrain and ear defects are seen in embryos mutant for Hoxa1 (Lufkin etal., 1991; Mark et al., 1993). Note that both kr/Mafb and Hoxa1 are expressed in the hindbrain but not in the otic vesicle itself; they are thus likely to influence otic pattern through the regulation of expression of secreted signalling molecules from the hindbrain (see below).

A dramatic alteration of $M L$ pattern is seen in the mouse Raldh2/- mutant, in which hindbrain segmentation is also severely disrupted. Here, there appears to be a complete lateralisation of the otic vesicle: expression of the medial marker Pax2 is lost altogether and the lateral marker $\mathrm{Hm} \times 3$ is expressed throughout the vesicle (Niederreither et al., 2000) (Fig. 3C, D). The otic vesicle is considerably smaller in the mutant, however, and it is possible that medial tissue is missing rather than having adopted lateral identity. As for kr/Mafb and Hoxa1, the otic patterning defects are likely to be due to loss of a signal from the hindbrain, since they are present at a stage when Raldh2 is expressed in the hindbrain but not in the ear. For all three mutants, a contributory factor to the otic phenotype may also be the abnormal position of the ear with respect to the hindbrain: the two tissues are no longer in close apposition, and the ear may thus simply be too far from the hindbrain source to receive the correct signal (Deol, 1964; Lufkin et al., 1991; Mark et al., 1993; Brigande et al., 2000b; Niederreither et al., 2000; Choo et al., 2006).

Signalling molecules derived from the hindbrain implicated in patterning the DV and $M L$ axes of the amniote ear belong to the same families as those with a role in otic AP patterning in the fish: Fgfs and Wnts. In the mouse kr/Mafb mutant hindbrain, r5 and r6 are replaced by an undivided rhombomere, which has r4-like identity and reduced Fgf3 expression (McKay et al., 1996; Choo et al., 2006). As the ear phenotype of $\mathrm{Fgf3}^{-1}$ embryos resembles that of kr/Mafb mutants (Mansour et al., 1993) the ear defects seen in $\mathrm{kr} / \mathrm{Mafb}$ are thought to be partly due to a reduction in Fgf3 signalling from the hindbrain (McKay et al., 1996). The Fgf3/- ear phenotype is, however, much less severe than that of $\mathrm{kr} / \mathrm{Mafb}$, suggesting that additional factors may be involved. Likewise, the $\mathrm{FgflO}^{-}$ear phenotype is very mild (Mansour et al., 1993). Note, however, that Fgfs also play a role in otic induction; as the double $\mathrm{Fgf3}^{-}$; Fgf10 $\mathrm{F}^{--}$mutant phenotype results in a drastic loss of otic tissue (Alvarez et al., 2003; Wright and Mansour, 2003), it is difficult to distinguish the early role of Fgfs in otic induction from a later (or concomitant) role in axial patterning.

In the mouse, Wnt signalling from the dorsal hindbrain appears to be a critical factor in the establishment of otic DV pattern, acting in part to restrict the ventralising effects of Shh signalling from the midline (see below) (Riccomagno etal., 2005). Wnt signals (Wnt1 and Wnt3a) derived from the dorsal hindbrain act locally on dorsal otic epithelium, but are thought to influence the whole DV axis of the ear, since Wnt-responsive cells in the dorsal otic vesicle contribute to the cochlea as well as dorsal derivatives. An additional factor from the dorsal hindbrain is also implicated in restricting the effects of midline-derived Shh signalling: ablation of the dorsal hindbrain results in an expansion of Shh-responsive markers (Pax2, Ngn1), which are unaffected in Wnt1\%; Wnt3a ${ }^{-1}$ double mutants, and this expansion is not fully rescued by constitutive activation of the Wnt pathway (Riccomagno et al., 2005). In the zebrafish tcf2 mutant, DV defects in otic patterning, like those along the AP axis, may also be attributable to the disruption of wnt 1 and wnt3a expression patterns in the dorsal hindbrain (Lecaudey et al., 2007), although this has not been functionally tested.

\section{Role of the midline in DV/ML patterning}

Tissues at the embryonic midline (notochord and floorplate) are ideally positioned to provide signals to impart ventral or medial pattern on the otic vesicle. Ablation of the notochord or floorplate alone, however, has no effect on ear patterning; the presence of either is sufficient for a correctly patterned ear in the chick (Bok et al., 2005). Ablation of both notochord and floorplate in the chick embryo adjacent to the otic vesicle at $\mathrm{HH} 10-11$ (E1.5, placode/ early otic cup stage), however, results in the loss of ventral otic derivatives (saccule and basilar papilla), demonstrating that ventral midline tissues are crucial for the acquisition of ventral otic identity in this organism. Likewise, rotation of the neural tube and notochord of E1.5 chick embryos such that the DV axis was inverted relative to the otic vesicle led to the acquistion of ventral identity in dorsal regions. Anteroventral markers, including $L f n g$, Six 1 and NeuroD, became expressed anterodorsally, adjacent to the rotated notochord and floorplate; a ventral marker (Otx2) expanded dorsally and expression of the dorsal marker Gbx2 was lost. Removal of the entire hindbrain together with the notochord in the r4-7 region of the chick embryo results in the development of a severely dysmorphic otic vesicle apparently lacking all ventral and dorsal character (Bok et al., 2005). Taken together, these data suggest that factors emanating from the ventral midline cooperate with those from the dorsal hindbrain and are both necessary and sufficient to induce ventral and dorsal otic character, respectively.

The strong sources of $\mathrm{Hh}$ expression at the ventral midline, adjacent to ventral and medial regions of the otic vesicle, make $\mathrm{Hh}$ an ideal candidate to impart ventromedial patterning information on the otic vesicle. Although in the zebrafish a loss of Hh signalling does not appear to cause overt DV patterning effects (Hammond et al., 2003), in amniotes, the loss of $\mathrm{Hh}$ signalling results in dramatic DV defects (Liu et al., 2002; Riccomagno et al., 2002; Bok et al., 2005). Analysis of $\mathrm{Sh}^{-/}$mouse embryos has shown that $\mathrm{Hh}$ from the floorplate and notochord is required for the specification of ventral otic regions: the cochlea, VIIIth ganglion and the lateral semicircular canal are absent or reduced (Liu et al., 2002; Riccomagno et al., 2002). Consistent with a loss of ventral otic regions, Otx 2 expression is absent, $D / x 5$ (dorsal) expression extends ventrally and Otx1, Fgf3, Lfng and Bmp4 domains shift ventrally (Fig. 3E, F). Medial and dorsal patterning is also affected: 
Pax2 is lost from the medial otocyst wall by E9.5, and Gbx2, which is required for ED development, is down-regulated, correlating with a failure to maintain ED outgrowth. These findings are corroborated by work in the chick embryo, where antibody-mediated inhibition of Shh signalling also results in ventral ear defects (Bok et al., 2005). Taken together, these data suggest a role for midlinederived Shh in patterning both the DV and ML axes of the amniote ear.

Interestingly, dorsal vestibular defects in $\mathrm{Sh}^{-/}$mutants can be completely rescued by mutation of one copy of the Gli3 gene. In the absence of $\mathrm{Hh}$ activity, Gli3 gives rise to a transcriptional repressor (Gli3R) of targets of Hh signalling. The authors suggest that the dorsal vestibular part of the ear is sensitive to the exact dose of Gli3R activity, while ventral structures require high activity of Gli activator proteins (Bok et al., 2007).

In the mouse, Shh is not only required but also sufficient for ventromedial otic specification. Transgenic embryos in which Shh is ectopically expressed throughout the otic vesicle display an expansion of ventral and medial markers (VIIIth ganglion, Pax2) and a reduction in dorsal $(D / \times 5)$ and lateral $(H m \times 3)$ markers. The cochlear duct is enlarged, but does not develop correctly (Riccomagno et al., 2002). Just as signalling from the dorsal hindbrain acts to suppress the ventralising effects of Shh to establish dorsal fates in the ear, the reciprocal relationship is also found: Shh acts to restrict the effects of Wnt signalling to the dorsal otic vesicle (Riccomagno et al., 2005). In the zebrafish, although a loss of $\mathrm{Hh}$ signalling does not appear to cause gross DV/ML patterning defects, our preliminary observations suggest that, as in amniotes, Hh signalling must be kept repressed for the correct acquisition of dorsal and lateral fates in the ear (KLH and TTW, unpublished data).

\section{Intrinsic factors for interpretation of $D V / M L$ patterning}

Components for the reception and transduction of Fgf, Wnt and Hh signalling are all expressed in the ear. Fgfr2(III)b is expressed in the dorsomedial otic vesicle juxtaposed to the hindbrain and is the receptor for both hindbrain- and otic vesicle-derived Fgf3 and Fgf10. The otic phenotype of the Fgfr2(III) $b^{-/}$receptor mutant

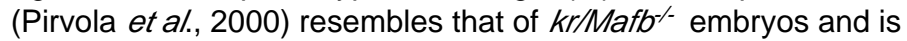
much more severe than the highly variable $\mathrm{Fgf3}^{\text {- }}$ phenotype (Mansour et al., 1993), suggesting that kr/Mafb may regulate more than one Fgf, or additional factors, in the hindbrain. Wnt signalling is actively received in dorsomedial otic tissue, as shown by activation of the Wnt-responsive reporter Topgal (Riccomagno et al., 2005). Expression of Ptc, Smo and Gli family transcripts, coding for the $\mathrm{Hh}$ receptor, transducer and effector, respectively, are expressed in otic epithelium and periotic mesenchyme in both zebrafish and amniotes (Riccomagno et al., 2002; Hammond et al., 2003; Ozaki etal., 2004; Bok etal., 2007). Moreover, in the mouse, conditional inactivation of Smo in the otic vesicle results in ventral otic defects, demonstrating that ventral otic epithelium responds directly to Shh signalling (Brown et al., 2007).

In amniotes, there is good evidence to show that mutations in some of the genes whose otic expression patterns are affected in response to disrupted hindbrain or midline signalling also lead to DV patterning defects in the ear. These genes-which include members of the DIx, Gbx, Hmx, Otx and Six families-may thus play an active role in the interpretation of extrinsic signals. In $D / \times 5^{-1}$; $\times 16^{-/-}$double mutants, expression of Gbx2 in dorsal regions of the developing ear is lost, and Pax2 expression expands throughout the otic vesicle. Consequently, all dorsal (vestibular) structures, including the endolymphatic duct, utricle, saccule and semicircular canals fail to form (Robledo and Lufkin, 2006). A similar phenotype is seen in $\mathrm{Hm} \times 2^{-} ; \mathrm{Hm}^{\prime-1}$ double mutants (Wang et al., 2004); loss of D/x5, Hmx2 or Hmx3 function alone also results in significant dorsal (vestibular) defects (Wang et al., 1998; Wang et al., 2001; Merlo et al., 2002). These may be key genes in the interpretation of signals from the dorsal hindbrain. For a summary of otic DV patterning in amniote embryos, see Fig. 6B.

The otic phenotype of $G b \times 2 \%$ mutants is strikingly similar to that seen in kr/Mafb mutants, providing compelling circumstantial evidence that $G b \times 2$ is a key gene for the interpretation of hindbrain signalling dependent on kr/Mafb function (Lin et al., 2005; Choo et al., 2006) (Fig. 4). In both mutants, there is a similar spectrum of variable phenotypes, with malformation of the most medial structures (ED, crus commune, anterior and posterior semicircular canals and saccule), while the lateral semicircular canal forms normally. In addition, ventral otic derivatives-the cochlea and spiral ganglion-are malformed in both mutants, even though Gbx2 is not expressed in ventral otic domains. This may be due, at least in part, to mutually repressive interactions between $G b \times 2$ and Otx2 (Lin etal., 2005; Choo etal., 2006; Miyazaki etal., 2006). $G b \times 2$ is required for $W n t 2 b$ and medial $D / \times 5 / 6$ expression, which is also lost in kr/Mafb mutants (Lin et al., 2005; Choo et al., 2006).

Otx genes are expressed in ventral otic epithelium, and have important roles in the development of the lateral (horizontal) semicircular canal and ventral otic derivatives. A loss of Otx1 function in both the mouse and zebrafish results in the loss of the lateral semicircular canal and incomplete segregation of the utricular and saccular maculae (Morsli et al., 1999; Fritzsch et al., 2001; Hammond and Whitfield, 2006). Otx2/- mice develop without a head, precluding an examination of the ear in these embryos; however, $\mathrm{Ot} \mathrm{1}^{-1-} ; \mathrm{Ot} \times \mathrm{2}^{+/-}$mice have much more severe cochlea and saccule defects than Otx $1 \%$ mice, indicating the importance of Otx2 for development of these structures (Morsli et al., 1999). As Otx2 expression is absent from otic vesicles of $\mathrm{Shh}^{-/}$mutants (see above), this may be a key gene in the interpretation of Shh signalling from the midline in the mouse.

Similarity has also been drawn between the $S h h^{-/}$mutant otic phenotype and that of Six $1 \%$ mice, in which there is a loss of ventral markers and an expansion of dorsal markers, including a dramatic enlargement of the Wnt2b expression domain corresponding to the endolymphatic duct and sac (Zheng et al., 2003; Ozaki et al., 2004). Expression of Six 1 in the otic vesicle, however, is not dependent on Shh signalling; likewise, expression of the Shhresponsive Ptc and Gli1 genes in the otic vesicle does not require Six1 function (Ozaki et al., 2004). It is thus unlikely that the ventralising function of Shh signalling in the mouse is mediated directly through Six1.

\section{Conservation of otic axial patterning mechanisms}

Many markers of axial patterning at the otic vesicle stage are highly conserved between zebrafish and amniotes (Table 1). Despite this, there is a puzzle: signals that are involved in AP patterning in the fish ear (Fgfs, Wnts, Hh) appear instead to contribute to otic DV patterning in amniote embryos (see Fig. 6). This may be partly due to simple differences in anatomical descrip- 
tion of the ear in the two groups. The entire zebrafish ear, which has no cochlea, corresponds to what is usually described as the "dorsal" or vestibular region of the amniote ear. In amniote embryos, the cochlear duct extends ventrally, and is usually considered a ventral structure; however, the cochlear duct arises from a site located posterior to the utricule, saccule and site of delamination of neuroblasts that forms the cochleovestibular ganglion (Riccomagno et al., 2002). Similarly, the Bmp4 expression domain that later marks the basilar papilla in the chick ear originates from a posteroventral region in the $\mathrm{HH} 24$ (E4) otocyst (Oh et al., 1996) (Fig. 1D). Thus, as for the zebrafish saccule, the cochlea can be considered a posterior structure as well as a ventral one, revealing many more similarities than differences in otic patterning between zebrafish and amniotes; note that the cochlea is thought to have evolved from the saccule (Fritzsch et al., 2002).

Some of the mutant phenotypes, however, do reveal genuine axial patterning differences between zebrafish and amniote ears, with the same markers clearly affected differently in equivalent mutant backgrounds. For example, in the mouse $S h^{-/}$embryo, otic Pax2 expression is downregulated, and the $B m p 4$ expression domain shifts ventrally, but these genes are not affected in zebrafish embryos in which Hh signalling is lost (Riccomagno et al., 2002; Hammond et al., 2003). Comparison of the mouse and zebrafish Mafb mutants ( $k r$ and $v a l$, respectively) reveals differences in the details of changes to hindbrain expression of Fgfs, and in the consequent otic patterning defects. In addition, a few region-specific markers in the otic vesicle are expressed differently: pax5, for example, is only expressed in the zebrafish and not the amniote otic vesicle, while otx 2 does not appear to be expressed in the zebrafish ear (Table 1).

If information from rhombomeres or rhombomere boundaries does play a role in AP patterning of the otic vesicle, it is interesting to note that there are differences in the positioning of the otic vesicle with respect to these boundaries in different vertebrate species (Murakami et al., 2004) (Fig. 5). In the lamprey, an agnathan (jawless) vertebrate, the otic vesicle arises opposite r4; in the zebrafish it initially arises opposite $r 4$ but is later positioned adjacent to $r 5$, while in amniotes, the ear is positioned even further posteriorly, next to $r 5$ and $r 6$. Gene expression patterns in the hindbrain, however-with a few exceptions, including those of Fgfs-are largely conserved, so that the otic vesicle is placed adjacent to different molecular influences in the different species. It has been suggested, for example, that changes in the expression pattern of $F g f 3$ in the hindbrain may have been a contributory factor in the evolution of the cochlea (Kwak et al., 2002). Nevertheless, despite differences in positioning of the otic vesicle relative to the rhombomeres, the $\mathrm{AP}$ restriction of many otic markers (e.g. $h m \times 3, t b \times 1)$ is conserved across species (Table 1), supporting the finding that in the chick at least, information from the hindbrain is not critical in establishing otic AP pattern (see above).

\section{Evolution of otic axial patterning}

The ears of adult agnathan vertebrates (hagfish and lampreys) appear tantalizingly symmetric about the AP axis, and it has been suggested that the complex labyrinth of the gnathostome (jawed vertebrate) ear evolved from a simpler structure with AP symmetry, containing a single sensory patch (Hagelin, 1974). As a result of this idea, it has been proposed that mutant phenotypes displaying enantiomorphic duplications of the ear may be atavisms (Léger and Brand, 2002). Recently, however, we have shown that the lamprey inner ear is much more asymmetric during embryonic stages than in the adult, and that it resembles the developing zebrafish inner ear in many respects. Morphological asymmetries in the shape and positioning of the macula communis, as well as asymmetries in hair cell polarity patterns, are obvious by late embryonic stages (stage 27-28). Molecular asymmetries similar to those observed in zebrafish are detectable earlier, in the otic vesicle. In particular, tbx 1 and fst are expressed in distinct posterior domains of the lamprey otic vesicle at stage 24 and 25, similar to the 24-30 hpf zebrafish otic vesicle (Sauka-Spengler et al., 2002; Hammond and Whitfield, 2006). Other studies in the zebrafish indicate that a single sensory macula does not necessarily indicate AP symmetry: atoh1a1b morphants, in which the sensory domain is undivided, retain a definite AP asymmetry (Millimaki et al., 2007), and otx1 morphants, in which the maculae are fused, also retain AP asymmetry (Hammond and Whitfield, 2006).

The lamprey data suggest that an otic vesicle with distinct AP asymmetry was already present in the common ancestor of lampreys and gnathostomes. However, we cannot exclude the possibility that the common ancestor of all vertebrates actually had a simpler AP symmetric inner ear. In particular, it will be interesting to see whether hagfish embryos have an otic vesicle that is more AP symmetric than in the lamprey, although it is unclear whether they can be considered a more ancestral species (Ota and Kuratani, 2006). As a deep-sea fish, virtually nothing is known about hagfish spawning behaviour, and their embryos have been almost impossible to collect; it is exciting to learn that hagfish embryos have recently been obtained in the laboratory (Ota et al., 2007; Ota and Kuratani, 2006).

\section{Conclusions}

Although several of the signalling components for the establishment of axial patterning in the otic vesicle have been identified (summarised in Fig. 6), the details of their mechanism of action are not simple and straightforward: synergy and antagonism between different signalling pathways and cross-talk between downstream effectors all contribute to the final pattern. The use of the same signalling pathways-Fgfs, Wnts and Hh-for patterning of the zebrafish otic AP axis and the amniote otic DV axis in part may simply reflect the different anatomical arrangement of the ear, revealing similarities between the DV axis of amniotes and the AP axis in the fish. It is clear that the axes are established at very early stages of development: asymmetric gene expression patterns are present in the otic placode as soon as it appears. Although the AP poles of the placode are equipotential, there may never be a symmetrical stage and so no requirement for a symmetry-breaking event. Symmetric ear phenotypes are therefore unlikely to represent atavisms, just as chick limbs with duplicated polarity do not mimic an ancestral condition. Areas that require further attention include a study of how axial informationas measured by asymmetric patterns of gene expression-is coupled to early pathways of otic placode induction and to later morphogenesis. This will require an understanding of how extrinsic signalling information is integrated in the developing otic 
placode and how regional patterning within the otic vesicle coordinates changes in cytoskeletal, cell junction and extracellular matrix components to effect the morphogenetic movements that sculpt the extraordinary labyrinthine structure of the mature inner ear.

\section{Acknowledgements}

We thank Leila Abbas and Fernando Giráldez for comments on the manuscript. lan Davies, an undergraduate project student, took the photographs in Fig. 3.

\section{References}

ABELLÓ, G., KHATRI, S., GIRÁLDEZ, F. and ALSINA, B. (2007). Early regionalization of the otic placode and its regulation by the Notch signaling pathway. Mech. Dev. 124: 631-645.

ALSINA, B., ABELLÓ, G., ULLOA, E., HENRIQUE, D., PUJADES, C. and GIRALDEZ, $F$. (2004). FGF signaling is required for determination of otic neuroblasts in the chick embryo. Dev. Biol. 267: 119-134.

ADAMSKA, M., LÉGER, S., BRAND, M., HADRYS, T., BRAUN, T. and BOBER, E. (2000). Inner ear and lateral line expression of a zebrafish $N k \times 5-1$ gene and its downregulation in the ears of FGF8 mutant, ace. Mech. Dev. 97: 161-165.

ALVAREZ, Y., ALONSO, M. T., VENDRELL, V., ZELARAYAN, L. C., CHAMERO, P., THEIL, T., BOSL, M. R., KATO, S., MACONOCHIE, M., RIETHMACHER, D. and SCHIMMANG, T. (2003). Requirements for FGF3 and FGF10 during inner ear formation. Development 130: 6329-6338.

ARNOLD, J. S., BRAUNSTEIN, E. M., OHYAMA, T., GROVES, A. K., ADAMS, J. C., BROWN, M. C. and MORROW, B. E. (2006). Tissue-specific roles of Tbx1 in the development of the outer, middle and inner ear, defective in 22q11DS patients. Hum. Mol. Genet. 15: 1629-1639.

BOK, J., BRONNER-FRASER, M. and WU, D. K. (2005). Role of the hindbrain in dorsoventral but not anteroposterior axial specification of the inner ear. Deve/opment 132: 2115-2124.

BOK, J., DOLSON, D. K., HILL, P., RÜTHER, U., EPSTEIN, D. J. and WU, D. K. (2007). Opposing gradients of Gli repressor and activators mediate Shh signalling along the dorsoventral axis of the inner ear. Development 134: 17131722.

BRIGANDE, J. V., ITEN, L. E. and FEKETE, D. M. (2000a). A fate map of chick otic cup closure reveals lineage boundaries in the dorsal otocyst. Dev. Biol. 227: 256-270.

BRIGANDE, J. V., KIERNAN, A. E., GAO, X., ITEN, L. E. and FEKETE, D. M. (2000b). Molecular genetics of pattern formation in the inner ear: Do compartment boundaries play a role? Proc. Natl. Acad. Sci. 97: 11700-11706.

BROWN, A. S., RICCOMAGNO, M. and EPSTEIN, D. J. (2007). Ventral inner ear progenitors are direct targets of hedgehog signaling. Society for Developmental Biology Abstracts, p. 253.

BURGESS, S., REIM, G., CHEN, W., HOPKINS, N. and BRAND, M. (2002). The zebrafish spiel-ohne-grenzen (spg) gene encodes the POU domain protein Pou2 related to mammalian Oct4 and is essential for formation of the midbrain and hindbrain, and for pre-gastrula morphogenesis. Development 129: 905916.

CHOO, D., WARD, J., REECE, A., DOU, H., LIN, Z. and GREINWALD, J. (2006). Molecular mechanisms underlying inner ear patterning defects in kreis/er mutants. Dev. Biol. 289: 308-317.

DEOL, M. S. (1964). The abnormalities of the inner ear in kreis/er mice. J. Embryol. exp. Morphol. 12: 475-490.

EKKER, S. C., MCGREW, L. L., LAI, C. J., LEE, J. J., VON KESSLER, D. P., MOON, R. T. and BEACHY, P. A. (1995). Distinct expression and shared activities of members of the hedgehog gene family of Xenopus laevis. Development 121: 2337-2347.

ELLIES, D. L., STOCK, D. W., HATCH, G., GIROUX, G., WEISS, K. M. and EKKER, M. (1997). Relationship between the genomic organisation and the overlapping embryonic expression patterns of the zebrafish $d / x$ genes. Genomics 45: 580590.

ERNEST, S., RAUCH, G.-J., HAFFTER, P., GEISLER, R., PETIT, C. and NICOLSON,
T. (2000). Mariner is defective in myosin VIIA : a zebrafish model for human hereditary deafness. Hum. Mol. Genet. 9: 2189-2196.

FRITZSCH, B., BEISEL, K. W., JONES, K., FARIÑAS, I., MAKLAD, A., LEE, J. S. and REICHARDT, L. F. (2002). Development and evolution of inner ear sensory epithelia and their innervation. J. Neurobiol. 53: 143-156.

FRITZSCH, B., SIGNORE, M. and SIMEONE, A. (2001). Otx1 null mutant mice show partial segregation of sensory epithelia comparable to lamprey ears. Dev. Genes Evol. 211: 388-396.

HADDON, C., JIANG, Y.-J., SMITHERS, L. and LEWIS, J. (1998). Delta-Notch signalling and the patterning of sensory cell differentiation in the zebrafish ear: evidence from the mind bomb mutant. Development 125: 4637-4644.

HADDON, C. M. (1997). The development of the zebrafish ear and a quest for genes involved in sensory patterning. PhD Thesis, The Open University.

HADRYS, T., BRAUN, T., RINKWITZ-BRANDT, S., ARNOLD, H.-H. and BOBER, E. (1998). Nk $\times 5-1$ controls semicircular canal formation in the mouse inner ear. Development 125: 33-39.

HAGELIN, L. O. (1974). Development of the membranous labyrinth in lampreys. Acta Zool. Suppl: 1-218.

HALL, E. K. (1939). On the duration of the polarization process in the ear primordium of embryos of Amblystoma punctatum (Linn.). J. Exp. Zool. 82: 173192.

HAMMOND, K. L., LOYNES, H. E., FOLARIN, A. A., SMITH, J. and WHITFIELD, T. T. (2003). Hedgehog signalling is required for correct anteroposterior patterning of the zebrafish otic vesicle. Development 130: 1403-1417.

HAMMOND, K. L. and WHITFIELD, T. T. (2006). The developing lamprey ear closely resembles the zebrafish otic vesicle: otx 1 expression can account for all major patterning differences. Development 133: 1347-1357.

HARRISON, R. G. (1936). Relations of symmetry in the developing ear of Amblystoma punctatum. Proc. Natl. Acad. Sci. 22: 238-247.

HARRISON, R. G. (1945). Relations of symmetry in the developing embryo. Trans. Conn. Acad. Arts Sci. USA 22: 238-247.

HAUPTMANN, G., BELTING, H. G., WOLKE, U., LUNDE, K., SOLL, I., ABDELILAHSEYFRIED, S., PRINCE, V. and DRIEVER, W. (2002). spielohne grenzen/pou2 is required for zebrafish hindbrain segmentation. Development 129: 16451655 .

HERBRAND, H., GUTHRIE, S., HADRYS, T., HOFFMANN, S., ARNOLD, H. H., RINKWITZ-BRANDT, S. and BOBER, E. (1998). Two regulatory genes, $C N k \times 5-$ 1 and $c$ Pax2, show different responses to local signals during otic placode and vesicle formation in the chick embryo. Development 125: 645-654.

HERNANDEZ, R. E., RIKHOF, H. A., BACHMANN, R. and MOENS, C. B. (2004). vhnf1 integrates global RA patterning and local FGF signals to direct posterior hindbrain development in zebrafish. Development 131: 4511-4520.

HIDALGO-SÁNCHEZ, M., ALVARADO-MALLART, R. and ALVAREZ, I. S. (2000). Pax2, OtX2, GbX2 and Fgf8 expression in early otic vesicle development. Mech. Dev. 95: 225-229.

KIERNAN, A. E., NUNES, F., WU, D. K. and FEKETE, D. M. (1997). The expression domain of two related homeobox genes defines a compartment in the chicken inner ear that may be involved in semicircular canal formation. Dev. Biol. 191: 215-229.

KIL, S.-H. and COLLAZO, A. (2001). Origins of inner ear sensory organs revealed by fate map and time-lapse analyses. Dev. Biol. 233: 365-379.

KIM, F. A., SING, L. A., KANEKO, T., BIEMAN, M., STALLWOOD, N., SADL, V. S. and CORDES, S. P. (2005). The vHNF1 homeodomain protein establishes early rhombomere identity by direct regulation of Kreisler expression. Mech. Dev. 122: 1300-1309.

KIMMEL, C. B., BALLARD, W. W., KIMMEL, S. R., ULLMANN, B. and SCHILLING, T. F. (1995). Stages of embryonic development of the zebrafish. Dev. Dyn. 203: 253-310.

KWAK, S.-J., PHILLIPS, B. T., HECK, R. and RILEY, B. B. (2002). An expanded domain of fgf3 expression in the hindbrain of zebrafish valentino mutants results in mis-patterning of the otic vesicle. Development 129: 5279-5287.

KWAK, S. J., VEMARAJU, S., MOORMAN, S. J., ZEDDIES, D., POPPER, A. N. and RILEY, B. B. (2006). Zebrafish pax5 regulates development of the utricular macula and vestibular function. Dev. Dyn. 235: 3026-3038.

LECAUDEY, V., ANSELME, I., ROSA, F. and SCHNEIDER-MAUNOURY, S. 
(2004). The zebrafish Iroquois gene iro 7 positions the $r 4 / r 5$ boundary and controls neurogenesis in the rostral hindbrain. Development 131:3121-3131.

LECAUDEY, V., ULLOA, E., ANSELME, I., STEDMAN, A., SCHNEIDERMAUNOURY, S. and PUJADES, C. (2007). Role of the hindbrain in patterning the otic vesicle: A study of the zebrafish vhnf1 mutant. Dev. Biol. 303: 134-143.

LÉGER, S. and BRAND, M. (2002). Fgf8 and Fgf3 are required for zebrafish ear placode induction, maintenance and inner ear patterning. Mech. Dev. 119: 91 108.

LILLEVÄLI, K., HAUGAS, M., MATILAINEN, T., PUSSINEN, C., KARIS, A. and SALMINEN, M. (2006). Gata3 is required for early morphogenesis and Fgf10 expression during otic development. Mech. Dev. 123: 415-429.

LIN, Z., CANTOS, R., PATENTE, M. and WU, D. K. (2005). Gbx2 is required for the morphogenesis of the mouse inner ear: a downstream candidate of hindbrain signaling. Development 132: 2309-2318.

LIU, W., LI, G., CHIEN, J. S., RAFT, S., ZHANG, H., CHIANG, C. and FRENZ, D. A. (2002). Sonic hedgehog regulates otic capsule chondrogenesis and inner ear development in the mouse embryo. Dev. Biol. 248: 240-250.

LUFKIN, T., DIERICH, A., LEMEUR, M., MARK, M. and CHAMBON, P. (1991). Disruption of the Hox-1.6 homeobox gene results in defects in a region corresponding to its rostral domain of expression. Cel/ 66: 1105-1119.

MANSOUR, S. L., GODDARD, J. M. and CAPECCHI, M. R. (1993). Mice homozygous for a targeted disruption of the proto-oncogene int-2 have developmental defects in the tail and inner ear. Development 117: 13-28.

MARK, M., LUFKIN, T., VONESCH, J.-L., RUBERTE, E., OLIVO, J.-C., DOLLÉ, P., GORRY, P., LUMSDEN, A. and CHAMBON, P. (1993). Two rhombomeres are altered in Hoxa-1 mutant mice. Development 119: 319-338.

MAVES, L. and KIMMEL, C. B. (2005). Dynamic and sequential patterning of the zebrafish posterior hindbrain by retinoic acid. Dev. Biol. 285: 593-605.

MCKAY, I. J., LEWIS, J. and LUMSDEN, A. (1996). The role of FGF-3 in early inner ear development: An analysis in normal and kreisler mutant mice. Dev. Biol. 174: $370-378$.

MERLO, G. R., PALEARI, L., MANTERO, S., ZEREGA, B., ADAMSKA, M., RINKWITZ, S., BOBER, E. and LEVI, G. (2002). The DIX5 homeobox gene is essential for vestibular morphogenesis in the mouse embryo through a BMP4mediated pathway. Dev. Biol. 248: 157-169.

MILLIMAKI, B. B., SWEET, E. M., DHASON, M. S. and RILEY, B. B. (2007). Zebrafish atoh1 genes: classic proneural activity in the inner ear and regulation by Fgf and Notch. Development 134: 295-305.

MIYAZAKI, H., KOBAYASHI, T., NAKAMURA, H. and FUNAHASHI, J. (2006). Role of $\mathrm{Gbx} 2$ and Otx2 in the formation of cochlear ganglion and endolymphatic duct. Dev. Growth Diff. 48: 429-438

MOENS, C. B. and PRINCE, V. E. (2002). Constructing the hindbrain: insights from the zebrafish. Dev. Dyn. 224: 1-17

MORSLI, H., TUORTO, F., CHOO, D., POSTIGLIONE, M. P., SIMEONE, A. and WU, D. K. (1999). Otx1 and Otx2 activities are required for the normal development of the mouse inner ear. Development 126: 2335-2343.

MOWBRAY, C., HAMMERSCHMIDT, M. and WHITFIELD, T. T. (2001). Expression of BMP signalling pathway members in the developing zebrafish inner ear and lateral line. Mech. Dev. 108: 179-184.

MURAKAMI, Y., PASQUALETTI, M., TAKIO, Y., HIRANO, S., RIJLI, F. M. and KURATANI, S. (2004). Segmental development of reticulospinal and branchiomotor neurons in lamprey: insights into the evolution of the vertebrate hindbrain. Development 131: 983-995.

NIEDERREITHER, K., VERMOT, J., SCHUHBAUR, B., CHAMBON, P. and DOLLÉ, P. (2000). Retinoic acid synthesis and hindbrain patterning in the mouse embryo. Development 127: 75-85.

OH, S.-H., JOHNSON, R. and WU, D. K. (1996). Differential expression of bone morphogenetic proteins in the developing vestibular and auditory sensory organs. J. Neurosci. 16: 6463-6475.

OTA, K. G., KURAKU, S. and KURATANI, S. (2007). Hagfish embryology with reference to the evolution of the neural crest. Nature 446: 672-675.

OTA, K. G. and KURATANI, S. (2006). The history of scientific endeavors towards understanding hagfish embryology. Zool. Science 23: 403-418.

OZAKI, H., NAKAMURA, K., FUNAHASHI, J., IKEDA, K., YAMADA, G., TOKANO, H., OKAMURA, H., KITAMURA, K., MUTO, S., KOTAKI, H., SUDO, K., HORAI,
R., IWAKURA, Y. and KAWAKAMI, K. (2004). Six1 controls patterning of the mouse otic vesicle. Development 131: 551-562.

PERA, E. and KESSEL, M. (1999). Expression of $D L X 3$ in chick embryos. Mech. Dev. 89: 189-193.

PFEFFER, P. L., GERSTER, T., LUN, K., BRAND, M. and BUSSLINGER, M. (1998). Characterization of three novel members of the zebrafish Pax2/5/8 family: dependency of Pax5 and Pax8 expression on the Pax2.1 (noI) function. Development 125: 3063-3074.

PIOTROWSKI, T., AHN, D.-G., SCHILLING, T. F., NAIR, S., RUVINSKY, I., GEISLER, R., RAUCH, G.-J., HAFFTER, P., ZON, L. I., ZHOU, Y., FOOTT, H., DAWID, I. B. and HO, R. K. (2003). The zebrafish van gogh mutation disrupts tbx 1 , which is involved in the DiGeorge deletion syndrome in humans. Development 130: 5043-5052.

PIRVOLA, U., SPENCER-DENE, B., XING-QUN, L., KETTUNEN, P., THESLEFF, I., FRITZSCH, B., DICKSON, C. and YLIKOSKI, J. (2000). FGF/FGFR-2(IIlb) signaling is essential for inner ear morphogenesis. J. Neurosci. 20: 6125-6134.

QIU, X., XU, H., HADDON, C., LEWIS, J. and JIANG, Y. J. (2004). Sequence and embryonic expression of three zebrafish fringe genes: lunatic fringe, radical fringe, and manic fringe. Dev. Dyn. 231: 621-630.

RAFT, S., NOWOTSCHIN, S., LIAO, J. and MORROW, B. E. (2004). Suppression of neural fate and control of inner ear morphogenesis by Tbx1. Development 131: $1801-1812$

RICCOMAGNO, M. M., MARTINU, L., MULHEISEN, M., WU, D. K. and EPSTEIN, D. J. (2002). Specification of the mammalian cochlea is dependent on Sonic hedgehog. Genes Dev. 16: 2365-2378.

RICCOMAGNO, M. M., TAKADA, S. and EPSTEIN, D. J. (2005). Wnt-dependent regulation of inner ear morphogenesis is balanced by the opposing and supporting roles of Shh. Genes Dev. 19: 1612-1623.

RILEY, B. B., CHIANG, M., FARMER, L. and HECK, R. (1999). The deltaA gene of zebrafish mediates lateral inhibition of hair cells in the inner ear and is regulated by pax2. 1. Development 126: 5669-5678.

RILEY, B. B., CHIANG, M. Y., STORCH, E. M., HECK, R., BUCKLES, G. R. and LEKVEN, A. C. (2004). Rhombomere boundaries are Wnt signaling centers that regulate metameric patterning in the zebrafish hindbrain. Dev. Dyn. 231: 278 291.

RILEY, B. B., ZHU, C., JANETOPOULOS, C. and AUFDERHEIDE, K. J. (1997). A critical period of ear development controlled by distinct populations of ciliated cells in the zebrafish. Dev. Biol. 191: 191-201.

ROBLEDO, R. F. and LUFKIN, T. (2006). DIx5 and DIx6 homeobox genes are required for specification of the mammalian vestibular apparatus. Genesis 44: 425-437.

SÁNCHEZ-CALDERÓN, H., MARTÍN-PARTIDO, G. and HIDALGO-SÁNCHEZ, M. (2002). Differential expression of Otx2, Gbx2, Pax2, and Fgf8 in the developing vestibular and auditory sensory organs. Brain Res. Bull. 57: 321-323.

SAUKA-SPENGLER, T., LE MENTEC, C., LEPAGE, M. and MAZAN, S. (2002). Embryonic expression of $T b \times 1$, a DiGeorge syndrome candidate gene, in the lamprey Lampetra fluviatilis. Gene Exp. Patt. 2: 99-103.

SU, Y. and MENG, A. (2002). The expression of $g b x-2$ during zebrafish embryogenesis. Mech. Dev. 113: 107-110

WALDMAN, E. H., CASTILLO, A. and COLLAZO, A. (2007). Ablation studies on the developing inner ear reveal a propensity for mirror duplications. Dev. Dyn. 236: 1237-1248.

WALSHE, J. and MASON, I. (2003). Fgf signalling is required for formation of cartilage in the head. Dev. Biol. 264: 522-536.

WANG, W., CHAN, E. K., BARON, S., VAN DE WATER, T. and LUFKIN, T. (2001) Hmx2 homeobox gene control of murine vestibular morphogenesis. Development 128: 5017-5029.

WANG, W., GRIMMER, J. F., VAN DE WATER, T. R. and LUFKIN, T. (2004). Hmx2 and $H m x 3$ homeobox genes direct development of the murine inner ear and hypothalamus and can be functionally replaced by Drosophila Hmx. Dev. Cell 7: 439-453.

WANG, W., VAN DE WATER, T. and LUFKIN, T. (1998). Inner ear and maternal reproductive defects in mice lacking the $H m \times 3$ homeobox gene. Development 125: $621-634$.

WRIGHT, T. J. and MANSOUR, S. L. (2003). Fgf3 and Fgf10 are required for mouse 
otic placode induction. Development 130: 3379-3390.

WU, D. K., NUNES, F. D. and CHOO, D. (1998). Axial specificiation for sensory organs versus non-sensory structures of the chicken inner ear. Development 125: 11-20.

WU, D. K. and OH, S.-H. (1996). Sensory organ generation in the chick inner ear. J. Neurosci. 16: 6454-6462.

XU, H., VIOLA, A., ZHANG, Z., GERKEN, C. P., LINDSAY-ILLINGWORTH, E. A and BALDINI, A. (2007). Tbx 1 regulates population, proliferation and cell fate determination of otic epithelial cells. Dev. Biol. 302: 670-682.
YNTEMA, C. L. (1955). Ear and Nose. In Analysis of Development, (ed. B. H. Willier P. A. Weiss and V. Hamburger), pp. 415-428. Philadelphia and London: W. B. Saunders.

ZHENG, W., HUANG, L., WEI, Z.-B., SILVIUS, D., TANG, B. and XU, P.-X. (2003). The role of Six1 in mammalian auditory system development. Development 130: $3989-4000$.

Published Online: 14th September 2007

Related, previously published Int. J. Dev. Biol. articles

See our Special Issue Ear Development edited by Fernando Giraldez and Bernd Fritzsch at: http://www.ijdb.ehu.es/web/contents.php?vol=51\&issue=6-7

Analysis of Netrin 1 receptors during inner ear development

Tanja Matilainen, Maarja Haugas, Jordan A. Kreidberg and Marjo Salminen

Int. J. Dev. Biol. (2007) 51: 409-414

Cell proliferation during the early compartmentalization of the Xenopus laevis inner ear Quincy A. Quick and Elba E. Serrano

Int. J. Dev. Biol. (2007) 51: 201-210

The origins of axial patterning in the metazoa: how old is bilateral symmetry? John R Finnerty

Int. J. Dev. Biol. (2003) 47: 523-529

Evidence for non-axial A/P patterning in the nonneural ectoderm of Xenopus and zebrafish pregastrula embryos.

E M Read, A R Rodaway, B Neave, N Brandon, N Holder, R K Patient and M E Walmsley Int. J. Dev. Biol. (1998) 42: 763-774

A conceptual framework for analyzing axial patterning in regenerating urodele limbs.

D L Stocum

Int. J. Dev. Biol. (1996) 40: 773-783

Alterations in gene expression during mesoderm formation and axial patterning in Brachyury (T) embryos. P Rashbass, V Wilson, B Rosen and R S Beddington

Int. J. Dev. Biol. (1994) 38: 35-44 